\title{
INDIANIDADE E DIVERSIDADE: O DISCURSO MIDIÁTICO SOBRE CRIME DE ESTUPRO NA ALDEIA BORORÓ
}

\author{
Indianity and Diversity: Indianidad y diversidad: \\ the Media Discourse upon a el discurso mediático sobre el crimen \\ Rape Crime at Bororó Village de la violación en aldea Bororó
}

\section{Elaine de Moraes Santos*}

Fabiana Biondo**

Universidade Federal de Mato Grosso do Sul, Faculdade de Artes, Letras e Comunicação, Campo Grande, MS, Brasil

\begin{abstract}
Resumo: A partir da veiculação de notícia sobre o estupro de uma criança de 9 anos na aldeia Bororó, em Dourados-MS, este artigo problematiza a forma como a diversidade cultural dos povos indígenas é textualizada no telejornal local MS Record. Sob a perspectiva discursiva de orientação francesa, aliada ao estudo de práticas sociais, analisa o modo como a mídia televisiva, ao colocar em questionamento aspectos da identidade cultural indígena - mediante sua suposta unicidade e legitimidade - promove um ataque aos direitos humanos e à diversidade, sobretudo pela contestação de "privilégios" dados aos indígenas. Entre as relações de poder inerentes ao discurso jornalístico e a historicidade do acontecimento em estudo, há o apagamento do próprio crime, relacionado à (falta de) indianidade. Em última instância, há a disseminação de um discurso preconceituoso e discriminatório sobre os indígenas, sobre a forma como são entendidos pela justiça e pelos órgãos de proteção a esses povos.
\end{abstract}

Palavras-chave: Cultura. Discurso. Diversidade. Mídia. Estupro.

\begin{abstract}
Based on news of the rape of a 9-year-old child at Bororó village, located in the city of Dourados, State of Mato Grosso do Sul, Brazil, this paper discusses how the cultural diversity of indigenous peoples is textualized in MS Record, the local TV news program. Supported by the French Line of Discourse Analysis and the study of social practices, this research analyzes how the television media, when questioning some aspects of the indigenous cultural identity through its supposed uniqueness and legitimacy, strikes out at the human rights and diversity, mostly contesting "privileges" given to indigenous people. Among the power relations inherent to the journalistic discourse and the historicity of the analyzed event, there is a effacement of the crime itself in relation to the (lack of) indianity. Ultimately, there is a dissemination of a prejudiced and discriminatory discourse towards them, particularly about how the courts and Brazilian indigenous protection organizations understand their own native people.
\end{abstract}

Keywords: Culture. Discourse. Diversity. Media. Rape.

Resumen: Desde la difusión de noticia sobre la violación de niño de 9 años en aldea Bororó en Dourados - Mato Grosso do Sul, Brasil, este artículo problematiza la forma como la diversidad cultural de pueblos

* Doutora em Letras. Docente da Universidade Federal de Mato Grosso do Sul. ORCID: https://orcid.org/0000-0001-8970-1564. E-mail: proflainemoraes@gmail.com.

** Doutora em Linguística Aplicada. Docente da Universidade Federal de Mato Grosso do Sul. ORCID: https://orcid.org/0000-0002-0443-4987. E-mail: fabibiondo@gmail.com. 
indígenas es textualizada en el telediario de noticias local llamado MS Record. Bajo el enfoque discursivo de orientación francesa, asociado con estudio de practicas sociales, analiza como la media de la televisión, cuando cuestiona aspectos de la identidad cultural indígena, delante de su supuesta unicidad y legitimidad, promueve un ataque a los derechos humanos y a la diversidad, especialmente por la contestación e "privilegios" concedidos a indígenas. Entre las relaciones de poder inherentes al discurso periodístico y la historicidad del acontecimiento en estudio, hay un borramiento del propio crimen relacionado con la (falta de) indianidad. También hay diseminación de un discurso de preconcepto y discriminación sobre los indígenas, sobre la manera como son entendidos por la justicia y por las instituciones de protección a eses pueblos.

Palabras clave: Cultura. Discurso. Diversidad. Media. Violación..

A pergunta é: até que ponto esse tratamento diferenciado dado aos indígenas tem sido eficaz no sentido de proteger essas comunidades? Será que essa mentalidade de que os costumes devem ser preservados tem sido realmente positiva ${ }^{1}{ }^{\text {(Transcrição livre) }}$

\section{INTRODUÇÃO}

As perguntas retóricas apresentadas na epígrafe constituem nossa premissa para uma reflexão sobre a forma como a diversidade cultural dos povos indígenas é textualizada no discurso de mídia televisiva de Mato Grosso do Sul. Transcritos de comentário tecido por jornalista durante a exibição de um telejornal local, os dizeres constituem uma reportagem acerca do crime de estupro que criança indígena teria sofrido dentro da própria aldeia.

Para além da motivação primeira que levou a apresentadora a questionar a necessidade desse respeito à diversidade étnica no Brasil - o acontecimento de um crime revoltante de estupro de criança2 -, nossa atenção recai aqui sobre a maneira como a prática discursiva (FOUCAULT, 2010a) midiática enquadra a cultura indígena. Isso significa, mais especificamente, pensar em como tal olhar pode contribuir para a manutenção de leitura discriminatória, e ainda colonial, a respeito das tribos existentes no país em pleno século XXI.

É nesse sentido que percebemos a necessidade de problematizar o modo como o estupro praticado no interior da aldeia é materializado nos fios discursivos do telejornal local MS Record - um programa de grande alcance na veiculação de informação sobre o estado e na formação de opinião acerca dos fatos que midiatiza. Definimos como corpus a notícia sobre o estupro de uma indígena de 9 anos na aldeia Bororó, em Dourados-MS, a qual foi exibida em 6 de outubro de 2014. Para viabilizar o processo analítico do cenário em questão, recorremos à perspectiva da Análise do Discurso (AD) de linha francesa, em sua vertente mais afinada aos pressupostos de Michel Foucault. Dialogamos, ainda, com

1 Menina de 9 anos pode ter sido estuprada por 15 homens. Vídeo disponível em: http://www.diariodigital.com.br/videos/menina-de-9-anos-pode-ter-sido-estuprada-por-15homens/7331/. Acesso em: 08 set. 2015.

${ }^{2}$ Embora repudiemos veementemente o fato ocorrido, a presente discussão não versa sobre a apuração do crime, suas causas e consequências, mas sim a respeito de como ele foi difundido na mídia local, que é formadora de opinião. 
outros campos, sobretudo com os aportes de teóricos que abordam a temática da diversidade cultural e estudam as questões identitárias que permitem a compreensão das relações entre os povos indígenas e os não indígenas.

Nas análises acerca do crime e da forma como ele foi discursivizado pela mídia, em vídeo hospedado no site do telejornal e disponível também no YouTube, observamos que há um processo de uniformização da identidade, pautada no ideal de "indianidade" (MAHER, 2016a) que residiria ontologicamente nos povos indígenas. Esse processo, como pretendemos mostrar, é baseado na marcação das diferenças entre indígenas e não indígenas, no questionamento da diversidade cultural e no apagamento do próprio crime de estupro, tido como parte de uma política de privilégios.

Nosso trabalho segue um caminho, no qual especificamos o conceito de cultura adotado e sua relação com a diversidade. Na sequência, tratamos da construção da identidade indígena enquanto processo sempre inacabado, não homogêneo, nem anterior à sua emergência em práticas sociais.

Na última seção, delineamos, primeiramente, a leitura da notícia em destaque como acontecimento histórico-discursivo, avaliando, principalmente, as condições de possibilidade (FOUCAULT, 2010b) que permearam o enquadramento da notícia. Por fim, mergulhamos na historicidade da trama (GREGOLIN, 2004) discursiva em estudo: a produção de um efeito discursivo discriminatório em Sequências Enunciativas3 (doravante SE) que, recortadas da regularidade4 (FOUCAULT, 2010a) inerente ao arquivo5 midiático, marcam o tom argumentativo da matéria jornalística em análise.

\section{A CULTURA INDÍGENA E A DIVERSIDADE CULTURAL}

Mesmo inserida nessa categorização tempo-espacial que é defendida por autores como Bauman (2001), Giddens (2009), Hall (2006) e Santaella (2007) como pósmodernidade, vemos que ainda é difícil para a sociedade brasileira, altamente etnocêntrica ${ }^{6}$, reconhecer que o mundo não gira em torno de sua forma de concebê-lo. Nesse sentido, o texto de Urquiza et al. (2014) é bastante pertinente para a reflexão acerca da história e da cultura indígena, principalmente ao explicar a significação do emprego de termos como diferença e diversidade em um âmbito conceitual, de forma que, inerente ao uso de um ou outro, residam perspectivas de compreensão da própria sociedade.

${ }^{3}$ Remontando às proposições de Foucault (2010a) sobre enunciado e função enunciativa, empregamos a sigla SE em referência às sequências enunciativas selecionadas.

${ }^{4}$ A regularidade discursiva "designa, para qualquer performance verbal (extraordinária ou banal, única em seu gênero ou mil vezes repetida), o conjunto das condições nas quais se exerce a função enunciativa que assegura e define sua existência" (FOUCAULT, 2010a, p. 163).

${ }^{5} \mathrm{O}$ arquivo é "o sistema que rege o acontecimento dos enunciados como acontecimentos regulares [...] é o que diferencia os discursos em sua existência múltipla e os especifica em sua duração própria” (2010a, p. 147-148).

${ }^{6}$ De acordo com Urquiza (2014, p. 11), “etnocentrismo é uma visão de mundo onde nosso próprio grupo é tomado com centro de tudo, e todos os outros são pensados e sentidos através dos nossos valores, nossos modelos, nossas definiçõos do que é a existência". 
Sobre diversidade, os autores reconhecem a maneira como é cada vez maior a pluralidade de empregos e de sentidos. A expressão mais completa, "diversidade cultural", significa "aquela que diz respeito às manifestações plurais de grupos e sociedades, em suas práticas culturais" (URQUIZA et al., 2014, p. 9). Os teóricos explicitam, pois, que, apesar de muitas pessoas ou mesmo muitos dicionários situarem diferença e diversidade como sinônimos, a distinção entre tais vocábulos é extremamente relevante porque a ideia de diversidade não se limita à comparação, de um "eu" com "um(uns) outro(s)", baseando-se em comportamentos ou traços individuais. A ideia de diversidade, segundo Gomes (2003), pertence ao nível das relações e é dotada de valores culturais, portanto, de valores também políticos e históricos.

Por seu lado, o trabalho com a noção de diferença diz respeito ao que se chama de "relação de alteridade", ou seja, "Ego (eu) e alter (outro)" (URQUIZA et al., 2014, p. 11). O problema é que a ideia de diferença traz consigo as contradições, os conflitos entre um "eu", em seu reconhecimento identitário, e a ideia etnocêntrica de que o "outro" é pior ou inferior. Na obra Povo Brasileiro ${ }^{7}$, do antropólogo Darcy Ribeiro (1995), por exemplo, temos acesso ao quanto foi nocivo para a história dos povos indígenas eles terem sido vistos sob um olhar que é orientado exclusivamente pela ideia de diferença.

Assim, uma perspectiva que considere a existência da diversidade, em especial por contribuição da Antropologia, segundo Urquiza et al. (2014, p. 12), é dotada de humanização, de práticas de trocas, de aprendizagem, de diálogo. Nas palavras dos autores, encontramos a concepção de que:

\begin{abstract}
[...] a diversidade não está relacionada somente a sinais aparentes, características físicas; de fato a diversidade cultural tem uma conotação cultural e política, isto é, tem um caráter relacional. Pode ter características observáveis, mas é, sobretudo, fruto de uma construção social e de poder que nos diferencia por razões históricas. Muitas vezes os grupos humanos tornam o outro diferente para fazê-lo inimigo, para dominá-lo. Por isso, falar sobre a diversidade cultural não diz respeito apenas ao reconhecimento do outro. Significa pensar a relação entre o eu e o outro. Não é só olhar para o reconhecimento do outro, mas pensar como eu, ao longo da minha história, me reconheço em relação aos outros.
\end{abstract}

Com base na perspectiva supracitada, entender a ideia de diversidade já nos leva a não comparar a cultura indígena com a não indígena, mas perceber que o Brasil é um país multicultural, ou seja, incutido no rótulo de pós-modernidade, é preciso que exista também a ideia de uma sociedade que efetivamente se concebe como tal, sobretudo nos modos de (con)viver com o outro.

Para pensar nessa diferença na organização da vida, podemos citar aqui o conteúdo do documentário Os rituais dos Sonacirema, ou mesmo a leitura de estudos/relatos antropológicos acerca de suas práticas, as quais podem causar estranhamento em outros grupos culturais. No que se refere aos ritos ligados à maneira como a existência material humana é vista e tratada no interior da cultura Sonacirema, por exemplo, a deformação, os rituais doloridos sob o rosto ou o corpo doente são impensáveis em um modelo de

7 O vídeo $O$ Povo Brasileiro (Matriz Tupi) 1/30. Disponível em: https://www.youtube.com/watch?v=pwQyYRGUS4c. Acesso em: 3 jul. 2014, às 12h, ilustra bem as contribuições do autor 
sociedade não indígena. Por outro lado, são facilmente identificáveis na prática constante da mesma sociedade, na adesão a cirurgias plásticas, ao uso de medicamentos perigosos para emagrecimento ou aquisição de músculos, ou ainda na submissão a exercícios intensos por atletas e pessoas descontentes com sua estrutura corporal.

É fato que parte dos costumes dos Sonacirema apontados no documentário podem causar surpresa e, por vezes, até certa repulsa entre aqueles que não compartilham de costumes similares. Cremos que o principal ponto para a discussão pode iniciar pela incursão na expressão usada por Mussi e Calderoni (2014, p. 8): "faz-se necessário um processo de descolonização de nossas mentes". Isso porque nossa cultura ainda se encontra contaminada pelas "marcas da colonialidade herdadas dos processos de nossa colonização" (MUSSI; CALDERONI, 2014, p. 8) - o que carece de uma ressignificação urgente.

Assim, com base em Mignolo (2003), é preciso compreender que, se os aspectos culturais sobre o corpo humano, entre outras especificidades da forma de viver dos Sonacirema, podem causar estranhamento, isso se dá porque estão marcadas, pelos estereótipos criados a respeito de indígenas ou de qualquer grupo, as concepções sociais de que existe uma única realidade. $\mathrm{O}$ autor nos convida a entender que a vida humana na Terra é assinalada pela pluralidade cultural, que pode e deve ser conhecida para que possamos compreendê-la em sua essência e, principalmente, respeitá-la.

As representações e os estereótipos construídos para os povos indígenas também podem ser pensados a partir de um trecho do clássico romance indianista Iracema, de José de Alencar, que reproduzimos a seguir:

\begin{abstract}
Além, muito além daquela serra, que ainda azula no horizonte, nasceu Iracema. Iracema, a virgem dos lábios de mel, que tinha os cabelos mais negros que a asa da graúna e mais longos que seu talhe de palmeira. $\mathrm{O}$ favo de jati não era doce como seu sorriso; nem a baunilha recendia no bosque como seu hálito perfumado. Mais rápida que a ema selvagem, a morena virgem corria o sertão e as matas do Ipu, onde campeava sua guerreira tribo, da grande nação tabajara. O pé grácil e nu, mal roçando, alisava apenas a verde pelúcia que vestia a terra com as primeiras águas. (ALENCAR, 1972, p. 25).
\end{abstract}

No excerto, identificamos uma visão romantizada (e deturpada) da índia ou da relação dos portugueses com os índios que aqui viviam, tal como se observa em outros textos da mesma fase na Literatura Brasileira. Uma análise interessante sobre esse processo foi realizada por Silviano Santiago (2014), por ocasião de sua conferência na UFMS, durante o III Colóquio NECC: Entrelugares Pós-Coloniais. Dentre as discussões realizadas pelo crítico literário, ressaltamos a passagem:

A descendência colonial de Caminha passa também pelo romântico José de Alencar e Iracema (1865), onde a metáfora bíblica ganha conotação amorosa e serve para traduzir o processo desigual e conturbado, embora pacífico, da posse pelo macho português da fêmea indígena. O licor de jurema, oferecido a Martin, escancara o escândalo da miscigenação sem estupro. O sêmen de Martim fertiliza o corpo virgem de Iracema e dele nasce o mestiço Moacir, cujo nome construído em tupi-guarani significa "filho do sofrimento". O político Alencar teria de deixar que o leitor entrevisse pela brecha da descendência a crueldade da colonização. (SANTIAGO, 2014, p. 14). 
Assim, paralelamente à visão romântica de indígena, existem as ideias desenvolvidas na Carta de Pero Vaz de Caminha, que parecem ter plantado a semente de uma visão que coloca o indígena como um povo não civilizado, no encalço do binarismo civilizado/não civilizado que constitui a sociedade como um todo. Talvez por isso, entre os estranhamentos que o contato com os Sonacirema pode causar, está a forma como esse povo era organizado e desenvolvido economicamente - duas características que não combinam entre si e nem com a ideia de selvageria ou falta de conhecimento, frequentemente atribuída aos indígenas e a outros povos, ao longo da história. Diante disso, reiteramos as ponderações de Mussi e Calderoni (2014, p. 21):

\footnotetext{
Para que um olhar "outro" sobre os povos indígenas seja construído é preciso problematizar como são e/ou foram construídas historicamente as representações e/ou apropriações estereotipadas que geram tantos preconceitos sobre as populações indígenas no Brasil. Esse índio conectado ao passado, ou quando muito com alguma presença pouco significativa na formação da colônia e na constituição do "povo brasileiro" é uma estratégia colonizadora que se mantém viva, como afirmamos, pela colonialidade.
}

O caminho ainda é longo e tortuoso, mas, certamente, ele passa pela produção do saber sobre a história e a cultura silenciadas por tanto tempo em prol da manutenção de determinada verdade, a qual se baseia unicamente na cultura ocidental não indígena. Com Foucault (2002), podemos questionar se existe de fato uma verdade ou realidade sobre qualquer povo ou temática, ou mesmo poderíamos entender, com o próprio Foucault (1979), que se trata muito mais de um efeito de verdade criado por diversos dispositivos de poder, como o discurso midiático, por exemplo.

\section{IDENTIDADE CULTURAL INDÍGENA E INDIANIDADE}

A exemplo do que Butler (1990) afirmara sobre o gênero em uma perspectiva pósmoderna das conexões entre linguagem e identidade, já se tornou consenso, nesse campo, que identidade não é um constructo que precede à ação social, mas sim um processo de construção, sempre local, situado e relacionado às relações de poder em configuração nas interações sociais. Estudos sobre questões indígenas, por sua vez, têm também afirmado a necessidade de que a identidade cultural não mais seja vista a partir de uma noção essencializada, mas sim como um processo de construção sempre passível de atualização (MAHER, 2016a; 2016b).

Nessa perspectiva, segundo Maher (2016a, p. 63), "nenhum traço cultural - língua indígena inclusive - é, em si mesmo, depositório ontológico de indianidade, até porque a identidade cultural indígena é algo que está sempre em construção". Não obstante, conforme a autora, há uma tendência muito forte, na sociedade como um todo, de se supor que a indianidade residiria ontologicamente nos povos (e línguas) indígenas, de tal forma que, ao indígena, restaria ser "refém" dos costumes de seus ancestrais e dos ideais sobre eles construídos, sob o risco de que seja perdida a "legitimidade" de sua filiação étnica. 
Em contraposição à tendência em questão, muitos atores indígenas vêm desafiando as representações preestabelecidas para seus povos, como as apresentadas no romance Iracema, mencionado antes. É nesse sentido, segundo Maher (2016a), que o deslocamento para as cidades e a apropriação de costumes tidos como de não indígenas (como o uso de tecnologias digitais) podem configurar outros modos de ensaiar e construir identidades étnicas, na contramão da tendência ao estabelecimento de uma suposta "autenticidade" da identidade indígena.

De modo análogo, tanto Pinto (1996) como Hall (2000), entre outros estudiosos, sugeriram que a ideia de pertencimento a um determinado grupo, seja ele racial, de gênero ou étnico, supõe sempre uma certa identificação. O processo de reconhecimento, porém, é mutável, passível de ressignificação; não se estabelece, portanto, a partir de um conjunto predefinido de traços identificatórios, e sim por meio de uma negociação constante de subjetividades.

Maher (2016b) lembra que a Antropologia há algum tempo abriu mão da definição de coletividades humanas pelo uso de parâmetros raciais. Segundo a autora, primeiramente o campo de estudos teria buscado substituir a ideia de raça pela de cultura, como forma de tentar combater uma caracterização por explicações deterministas. No decorrer do século XX, entretanto, os antropólogos começaram a colocar em suspenso a própria noção de cultura, evidenciando-a em seu potencial de levar a análises reducionistas.

\footnotetext{
Segundo uma concepção essencialista de cultura, a somatória de traços culturais fixos definiriam um grupo étnico. Visto dessa maneira, um índio seria aquele que usa arco e flecha, anda nu, enfeita-se com penas e urucum e fala uma língua indígena, se essas, por exemplo, tivessem sido as dimensões eleitas pelo grupo étnico ao qual pertence como marcas irredutíveis de sua identidade (MAHER, 2016b, p. 721).
}

Ao chamar a atenção para uma visão estática do fenômeno, a noção essencialista vai em direção contrária à identificação das culturas em sua perspectiva dinâmica, sempre em transformação, conforme pontua a autora. Do ponto de vista de pesquisas sobre identidade indígena, tal visão corroboraria um ideal de indianidade pautado na identificação das diferenças, não da diversidade, conforme distinção que propusemos anteriormente. Em contrapartida, quando o que está em foco é a diversidade, o escopo da questão recai sobre as possibilidades identitárias a serem ensaiadas socialmente pelos sujeitos, mais como um "devir" que como um elemento estável e predeterminado.

Essa percepção da identidade indígena a supõe como fenômeno emergente, construído em situações sociais e passível de ressignificações, conforme vimos pontuando, embora, para Maher (2016b), como forma de dominação de grupos étnicos, sejamos levados a apagar singularidades e provisoriedades, e a tomarmos tais grupos de forma generalizada. No caso dos indígenas, lembra a autora, vivenciamos uma história de afirmação de um "índio genérico", em apagamento à existência de aproximadamente 220 povos indígenas diferentes no território brasileiro, reduzindo todos eles a "índios" e os definindo a partir de categorias e características comuns a uma coletividade.

Advogando em outra direção, a autora afirma que 
[...] a definição de um grupo étnico reside na identificação que seus membros fazem de si mesmos e de outros para se organizarem e interagirem socialmente: é índio, então, quem se define como tal e define seu interagente como não-índio. Por isso, afirma Barth (1916:16), a identidade étnica envolve o estabelecimento de fronteiras de identificação entre o "nós" e o "eles". (MAHER, 2016b, p. 722, grifos no original)

Desse ponto de vista, não seria a cultura indígena que definiria o que é ser índio, "ao contrário, porque o indivíduo é índio, a cultura de que ele é portador é definida como sendo indígena" (MAHER, 1996, p. 19). Na contramão de tal perspectiva e servindo a interesses políticos específicos, quando a constituição cultural e identitária de indígenas é delegada às palavras de terceiros, ou de não-índios - como é o caso da apresentadora cuja reportagem analisamos, há sempre a possibilidade de que o olhar se constitua como um efeito de verdade, tal como pontuamos na seção anterior.

\section{A DISCURSIVIZAÇÃO DO CRIME DE ESTUPRO NA ALDEIA BORORÓ}

Para nosso gesto de leitura (ORLANDI, 1996) de como a diversidade cultural dos povos indígenas é textualizada no discurso da mídia televisiva, escolhemos a matéria intitulada "Menina de 9 anos pode ter sido estuprada por 15 homens", a qual faz referência a crime ocorrido em um domingo, primeiro dia das eleições de 2014, em 5 de outubro, na cidade de Dourados, estado de Mato Grosso do Sul, e exibida pelo telejornal local $M S$ Record $-1^{a}$ edição ${ }^{8}$, um dia depois. Para termos acesso a ela, utilizamos o vídeo hospedado no site do programa, através do link http://www.diariodigital.com.br/ a partir do dia 7 do mesmo mês e ano.

Com a duração de $4 \min 19 \mathrm{~s}$, nosso objeto de análise foi exibido pela apresentadora Glaura Villalba, com a participação da repórter Miriam Névola e imagens de Adalberto Domingos. Nos primeiros 1 min47s, Villalba anuncia a notícia e comenta o fato. Posteriormente, ela chama a exibição da matéria em si, a qual dura 1 minuto e 45 segundos, com cenas cujos trechos de fala da repórter Miriam Névola são desenvolvidos em lugares/situações alternados: a) em construção próxima ao endereço da vítima; b) na parte ao hospital em que a garota estuprada foi atendida; c) na entrada do conselho tutelar da cidade; d) em entrevista com a conselheira tutelar; e) na frente da delegacia e f) em situação de entrevista com Rosely Galego, delegada responsável pela condução das investigações, para, depois, voltar a ser comentada novamente em estúdio pela apresentadora.

Em um primeiro momento, a configuração da notícia mostra-se como tradicional, uma vez constituída de anúncio em estúdio e cenas externas que ambientam tanto os fatos quanto as entrevistas com pessoas envolvidas. É no comentário em estúdio, no entanto, que encontramos o objeto motivador deste texto. Pela sua importância, realizamos uma transcrição livre, dividindo em sequências enunciativas menores os trechos selecionados para discussão.

\footnotetext{
${ }^{8}$ O MS Record é um telejornal brasileiro criado em 2008, exibido pela chamada TV MS Record, afiliada da Rede Record de Televisão, em duas edições: uma pela manhã e outra no fim da tarde, com horários que variam de ano para ano.
} 
Na primeira sequência, a jornalista anuncia a notícia, apresentando o que aconteceu e como sua equipe foi atrás dos fatos:

\begin{abstract}
SE1: Que uma menina indígena, de 9 anos de idade, pode ter sido estuprada por 15 homens, 5 já foram confirmados pela polícia, 3 estão presos. O caso aconteceu na noite do último domingo e detalhe, domingo de eleições, com lei seca em vigor, e os acusados, que estão presos, afirmam que estavam todos bêbados. Hoje de manhã, quando nossa equipe foi até a casa da menina, que mora com a avó na aldeia, encontrou a senhora indígena aparentemente alcoolizada, sem condições de nos receber. Aliás, todos que estavam na casa, estavam aparentemente bêbados (DIÁRIO DIGITAL - transcrição livre).
\end{abstract}

Na SE1, a violência sofrida por criança de 9 anos é apresentada, com a devida modalização "pode ter sido estuprada" (acerca da ainda não comprovada participação de 15 homens no ato em si). Do anúncio de abertura, são explicitadas algumas informações sobre o andamento das prisões efetuadas, e a data do ocorrido também é apresentada, com a contextualização de que se tratou do mesmo dia em que aconteceu o primeiro turno das eleições brasileiras de 2014. A referência a tal fato se perfaz no resgate à lei nacional de proibição do consumo de bebida alcoólica no país.

A nosso ver, a menção se justifica na medida em que a apresentadora situa os suspeitos apreendidos pela polícia (a avó da vítima e demais parentes presentes na casa), respectivamente, como pessoas que "estavam todos bêbados" e "estavam aparentemente bêbados”. A referência ao uso de álcool (não confirmado na época) já delineia um viés argumentativo à discursivização da jornalista, cujos efeitos de sentido possíveis levam para uma acusação de maus tratos à criança pela própria família. Além disso, remetem a um discurso generalizado sobre indígenas de Mato Grosso do Sul, muitas vezes rotulados como alcoólatras e ligados a ações de barbárie - um discurso associado ao constructo de um imaginário de selvageria historicamente vinculado a todo o grupo étnico em questão.

A partir do enunciado, a apresentadora dá início à produção de comentário avaliativo em que lança uma série de perguntas retóricas e de julgamentos do caso, imprimindo sua posição acerca do ocorrido antes mesmo de tratar dos demais dados da reportagem gravada. Pelo teor dos dizeres e a heterogeneidade de aspectos levantados, resgatamos a fala mencionada em trechos separados, a começar pela recuperação da epígrafe deste trabalho:

SE2: A pergunta é: até que ponto esse tratamento diferenciado dado aos indígenas tem sido eficaz no sentido de proteger essas comunidades? Será que essa mentalidade de que os costumes devem ser preservados tem sido realmente positiva? (DIÁRIO DIGITAL transcrição livre).

Na SE2, como se vê, a jornalista questiona o denominado "tratamento diferenciado" que os indígenas recebem, no que se refere aos direitos adquiridos com muita luta, e indaga se isso de fato tem eficácia na proteção das comunidades. Em seguida, ela faz uso do substantivo "mentalidade" em questionamento aos discursos dos órgãos de proteção e das próprias lideranças indígenas quanto à relevância da manutenção dos costumes, e, portanto, do respeito à diversidade cultural indígena. 
Mais que desqualificar uma mentalidade comum a certos grupos ativistas ou às próprias lideranças quanto ao respeito à diversidade, o que se desconsidera na fala em análise é o conteúdo da própria Constituição Federal Brasileira, a qual, em seu artigo 231, dispõe sobre o direito à preservação de costumes, tradições e crenças: "São reconhecidos aos índios sua organização social, costumes, línguas, crenças e tradições, e os direitos originários sobre as terras que tradicionalmente ocupam, competindo à União demarcálas, proteger e fazer respeitar todos os seus bens" (BRASIL, 1988).

Apesar desse reconhecimento, ainda que tardio, por parte da legislação nacional, não podemos esquecer que a mesma legislação "menciona o propósito de preservar sua cultura, porém, impõe a sua sujeição à aplicação das leis do País, nos mesmos termos em que se aplicam aos demais brasileiros". (OLIVEIRA et al., 2013, p. 304).

Como justificativa para as duas perguntas retóricas (sequência enunciativa 2), a jornalista continua seu comentário, situando discursivamente a violência entre indígenas como algo que ocorre "da mesma forma", ou seja, ressaltando haver a manutenção dessa prática entre as tribos apesar dos esforços de proteção advindos de uma sociedade não indígena:

\begin{abstract}
SE3: Porque o que a gente observa é que a violência ocorre da mesma forma e é até pior, agravada pela miséria. E quando vemos notícias como essa, é impossível não pensar que as leis precisam ser mudadas, que esse protecionismo é tolo e nocivo (DIÁRIO DIGITAL transcrição livre).
\end{abstract}

Como se pode observar, na SE3, a existência de violência nas tribos é caracterizada a partir de um grau que a apresentadora do telejornal qualifica como "pior" e reafirmada pelo que seria um elemento determinante à manutenção dessa prática nas comunidades: "agravada pela miséria". As condições sociais mencionadas não aparecem, porém, como dado no restante da reportagem, e elas são utilizadas em um discurso que homogeneíza a situação indígena seja no estado, seja no país como um todo.

Ainda na SE3, sob o uso da primeira pessoa do plural, "vemos", a jornalista enuncia, colocando-se como representante da fala não indígena, quando reafirma a necessidade de questionar as leis existentes, enquanto fruto do que designa por "protecionismo tolo e nocivo" - qualificação que desrespeita e acusa a pertinência da legislação em prol dos direitos indígenas.

Ao evocar a necessidade de alteração nas leis, a jornalista faz migrar o objeto em discussão, a priori pertencente a um domínio midiático, convocando o discurso jurídico como a solução ordenada, consciente, neutra, lógica e transparente. E ela o faz ignorando, com isso, a diversidade social, étnica e cultural que deveria pautar o respeito a todos os brasileiros, permitindo-lhes sim um julgamento em conformidade à sua existência não homogênea. O que ela desconsidera com essa assertiva é, então, que:

\footnotetext{
[...] as normas jurídicas silenciam o índio, tornando-o inexistente na consciência nacional. A abordagem da questão indígena nesses discursos normativos funciona, ao menos, como indício de apagamento das diferenças ao dispor sobre tratamento igualitário entre os índios e demais grupos que compõem a população nacional. (OLIVEIRA et al., 2013, p. 305).
} 
Após fazer uso de um discurso que nega a diversidade cultural indígena e dissemina uma série de elementos pejorativos e totalizantes sobre traços de comportamento desses povos, a própria apresentadora nega haver qualquer teor discriminatório em sua fala:

SE4: E isso não é uma questão de raça, nem uma bandeira discriminatória, pelo contrário, será que não está na hora de a sociedade incorporar os indígenas? (DIÁRIO DIGITAL transcrição livre).

$\mathrm{Na}$ SE4, a negação da diversidade cultural indígena se perfaz novamente no apagamento do fato de que todas as afirmações realizadas desde o início do comentário jornalístico, registrado neste trabalho por SE1, SE2 e SE3, tratam sim de uma questão de raça - tida como atributo identitário a reafirmar um "índio genérico" (MAHER, 2016b, p. 723). Por fim, reforçando não levantar nenhum tipo de bandeira discriminatória, a jornalista lança mais uma questão retórica, chamando para a sociedade a responsabilidade de "incorporar" os povos indígenas.

Entre os significados associados ao verbo "incorporar" no dicionário online Priberam da Língua Portuguesa, encontramos, como quinta e sexta acepções do verbete, as definições "incluir" e "admitir como membro ou indivíduo". Apesar de a apresentadora do telejornal reclamar, então, a inclusão dos indígenas ou a admissão deles como membros da sociedade brasileira, ela o propõe, contrariamente, a partir da própria negação de etnia e da homogeneização da identidade indígena.

A incorporação requerida no discurso da jornalista é, portanto, avessa ao caráter intercultural necessário à convivência com a diversidade em um país como o Brasil. De acordo com Warren (2002), uma visão interculturalista considera relevantes as raízes originárias de cada grupo social, de forma que as identidades sejam tidas como fruto de processos de trocas intersubjetivas, comunicativas, de negociação e busca de consensos mínimos entre os indivíduos ou grupos, isto é, que sejam vistas como identidades plurais. E os valores, nessa concepção, devem ser observados a partir de níveis mais moleculares do cotidiano (desde relações afetivas, fraternais, comunitárias até a esfera pública e política). Assim, na tensão entre a busca de igualdade, mas que considere o direito à diferença, a autora sugere um processo dialógico que contemple a diversidade em níveis razoáveis e, a partir de políticas compensatórias, contribua para a superação das desigualdades seculares.

No caso da histórica relação que marcou o contato dos indígenas com os não indígenas, desde a chamada Colonização, vários foram os esforços de compensar a desigualdade e garantir o direito mínimo. Um dos exemplos concretos é o texto da Constituição Federal já aludido. Esse movimento compensatório pode ser avaliado, à luz de Foucault (2010a, p. 24), quando o filósofo francês explica como, no convívio entre saber e poder, permite-se "estabelecer entre os fenômenos simultâneos [...] de uma determinada época uma comunidade de sentido, ligações simbólicas, um jogo de semelhança e de espelho - ou que fazem surgir, como princípio de unidade e de explicação, a soberania de uma consciência coletiva".

Na definição do que seria tal incorporação, na SE5, mais uso do conectivo "porque" é acionado como justificativa da jornalista para o tom discursivo de sua fala: 
SE5: Porque mais importante que preservar a cultura, é preservar a vida. E da forma como está, os próprios índios estão se matando entre si. Eles assistem televisão, têm acesso à internet, têm celulares, usam as roupas que todos nós usamos. Nessas condições em que vivem hoje, eles têm que ser protegidos do quê? E o que vai ser dessa menina? (DIÁRIO DIGITAL - transcrição livre).

Na SE5, o efeito discriminatório perpassa explicitamente a negação da necessidade de preservação da diversidade cultural indígena, com a justificativa de que é preciso "preservar a vida", como se as duas instâncias - vida e cultura - não fossem interligadas. Na esteira da negação e do equívoco teórico, imprime-se um lado selvagem aos indígenas, na afirmação de que "os próprios índios estão se matando entre si". No cerne de um enunciado como esse, que atribui aos indígenas uma característica autodestrutiva, vem à tona um discurso dicotômico de comparação entre dois povos: civilização versus selvageria, de forma que:

[...] é sob a égide da disputa de sentidos que se estabelece como conflito fundamental a civilização versus a selvageria, conflito do qual se derivam os demais conflitos: índios versus não índios; costumes indígenas versus as leis da civilização [...] a diferença é transformada em desigualdade, que se transforma em justificativa pertinente para a segregação e exclusão (OLIVEIRA et al., 2013, p. 298).

Na sequência da segregação discursiva mencionada pelos autores citados, a fala da apresentadora do telejornal ainda enumera especificidades do acesso de algumas tribos à televisão, internet e celulares, e o faz traçando um paralelo com os hábitos da sociedade não indígena. Para tanto, há, inclusive, o questionamento ao fato de os indígenas usarem roupas "como todos nós usamos". Na comparação, a utilização da primeira pessoa do plural delimita bem o tipo de interlocutor a que se destina sua fala: os não indígenas. Assim, observamos uma espécie de quebra de expectativas sobre o que, em tese, constituiria um padrão de legitimidade aos povos nativos (selvagens que não "assistem televisão, têm acesso à internet, têm celulares, usam as roupas que todos nós usamos"). Trata-se, portanto, da marcação de diferenças entre índio e não-índio como justificativa para a negação cultural.

Diante disso, o que vemos ecoar no comentário exibido no telejornal são "os sentidos e o estereótipo do índio, formulados pelos não-índios - já têm definidos o índio e sua prática social: seres que vivem e se relacionam diferentemente, fora do padrão" (OLIVEIRA et al., 2013, p. 291-292). Com eles, são silenciados os processos de imposição e, mesmo, de assimilação deliberada da cultura ocidental pelos indígenas que passaram a fazer uso de artefatos não procedentes de seu povo, de modo a desafiar a tendência histórica a relacionar sua identidade aos costumes de seus ancestrais, sob ameaça da perda de uma uma suposta legitimidade relativa à indianidade. Da forma como enuncia, os dizeres midiáticos deslizam sentidos de que "o próprio indígena é significado como um simulacro, porque não há coincidência de sua imagem real com o imaginário do não índio" (OLIVEIRA, et al., 2013, p. 297).

Entre os equívocos contemporâneos a respeito dos povos indígenas, está a própria denominação a eles atribuída, já que, sob o mesmo termo, costuma-se se englobar uma infinidade de etnias cujas diferenças culturais, históricas, sociais e até políticas são extremamente significativas. Nessa distinção, não só questões de aparência, mas também 
as próprias crenças, a culinária, a organização familiar, entre outros aspectos, são especificidades variáveis e incompatíveis com qualquer prática de homogeneização da cultura indígena:

\begin{abstract}
Esquece-se que, por trás dessa categoria genérica, se estende uma ampla diversidade cultural, linguística, de contato, de histórias de contato com os segmentos da nossa sociedade, de formas de organização social, de formas de entender o mundo, de se posicionar dentro do mundo. (Trecho transcrito da parte I do vídeo "Povos Indígenas: conhecer para transformar").
\end{abstract}

Conforme o antropólogo Luiz Donisete Grupioni, parte II do vídeo "Povos Indígenas: conhecer para valorizar", outro equívoco muito comum é achar que indígenas não possuem fé, lei ou conhecimento - dado que não são dotados, muitas vezes, de um código escrito próprio. Existe, ainda, uma visão infundada de que tais povos pararam no tempo e não passaram por transformações - uma espécie de ficção de que, como selvagem, o indivíduo nativo mantém o mesmo perfil descrito no descobrimento do Brasil: o de um ser da floresta, desprovido de roupas e de estudo.

Ao final da sequência enunciativa 5, por fim, a jornalista questiona, com mais uma pergunta retórica, a real necessidade de proteção às etnias: "eles têm que ser protegidos do quê?" No bojo da indagação proferida, temos acesso a uma memória discursiva acerca do que representou às tribos indígenas a criação, em 1910, do SPI - Serviço de Proteção aos Índios. Mussi (2014) explica, com base em Oliveira (1960), que apesar do papel um tanto quanto protecionista desse órgão, seu surgimento foi fundamental para minimizar a violência do trabalho escravo ao qual estavam submetidos, sobretudo os Terena ${ }^{9}$, que eram bons agricultores e seguiam explorados por fazendeiros locais: "com a criação das Reservas, os Terena teriam condições superiores em relação à fase de 'cativeiro', cujo período se arrastava desde a guerra do Paraguai” (OLIVEIRA, 1960, p. 70).

Por outro lado, segundo Borges (2013, p. 256, grifos da autora), inerente ao emprego do substantivo proteção, coexiste uma rede de produção de sentidos em que se promove a "manutenção das práticas civilizatórias e o efeito de evidência, pela ideologia, de que a União assiste, protege, civiliza, incorpora, expande, nacionaliza e comunga, ou seja, cria estratégias para ensinar o silvícola a ser nacional". Isso significa que, quando se defende o serviço em nome de uma proteção, silencia-se, por outro lado, "a resistência, o movimento indígena historicamente construído" (BORGES, 2013, P. 256).

Paralelo à implantação das reservas, teve início um processo de segregação daqueles que passaram à condição social denominada "tutelados". Usando a perspectiva teórica foucaultiana ${ }^{10}$ acerca das relações de poder, Lima (1995) discute como o exercício do poder tutelar acaba se concretizando em uma espécie velada de guerra, uma vez que esse sistema permite novas formas de dominação, de separação, de exclusão e de silenciamento. Apesar de repudiarmos o jeito como interdiscursivamente a apresentadora questiona a proteção à cultura indígena, entendemos o caráter dominante da criação de um órgão como o SPI e inclusive fazemos eco às palavras de Borges (2013, p. 252):

\footnotetext{
${ }^{9}$ Etnia indígena brasileira que se concentra em especial no Estado de Mato Grosso do Sul.

${ }^{10}$ Entre as obras do filósofo francês que discutem essa questão das relações de poder, podemos citar $A$ ordem do discurso (2010b) e Mcrofísica do poder (1979).
} 
No caso do Serviço de Proteção ao índio (SPI), proteger o índio genérico, ou seja, desconsiderando as peculiaridades de cada povo, sua diversidade, funciona como um serviço administrativo da União. A nominalização proteção que predica serviço estabelece o tipo de serviço: o de proteger, antes fundamentado numa prática administrativa que é pautada pela relativa incapacidade jurídica, mas esse processo, pelo preenchimento semântico do termo proteção enquanto produto fica apagado. Essa é uma prática linguística de mascaramento das relações de poder que funda, pelo texto da lei, a tutela sob uma suposta incapacidade [...] (grifos da autora).

A justificativa final constante na SE5 é calcada em indagação quanto ao futuro da vítima após o crime de estupro. No encerramento do primeiro bloco de comentário, a jornalista anuncia a exibição da reportagem, tratando da equipe que, segundo ela, está igualmente chocada com o fato ocorrido na aldeia:

\begin{abstract}
SE6: Vamos assistir à reportagem, depois vamos falar mais sobre esse caso. No ar, o trabalho dos nossos profissionais em Dourados, Adalberto Domingos e Miriam Névola, que estão igualmente chocados com o que aconteceu, pode rodar. (DIÁRIO DIGITAL - transcrição livre).
\end{abstract}

Após realizar a chamada (SE6), o telejornal passa a exibir, por 1 minuto e 45 segundos, as gravações que tratam de como a vítima foi encontrada na aldeia Bororó, em Dourados-MS, das suas condições no momento do resgaste (chorando e sangrando), de com quem vive e de como a menina foi retirada de perto da avó, por parentes, para sofrer as agressões em uma construção.

As entrevistas da delegada e da conselheira tutelar, responsáveis pelo acompanhamento do caso, são exibidas para veicular informações acerca do estado de saúde da menina, dados sobre os acusados e detalhes acerca da investigação. Mostradas as cenas externas, o telejornal volta para o estúdio com nova participação da apresentadora na continuação de seu comentário sobre o fato:

\begin{abstract}
SE7: A menina passou por uma cirurgia ontem, de reconstrução das partes íntimas e não corre risco de morte. Ela está internada na ala pediátrica de um hospital de Dourados. Os outros suspeitos estão sendo procurados pela Força Nacional, que é responsável pela segurança na aldeia. As informações que temos é que outras ocorrências de estupros entre indígenas, chamadas feirinhas, já foram registradas pela polícia em Dourados. (DIÁRIO DIGITAL - transcrição livre).
\end{abstract}

Em SE7, são introduzidas informações sobre a cirurgia a que a criança tinha sido submetida e suas atuais condições de saúde, bem como há a referência à procura por outros suspeitos de realizar o que se tem chamado na aldeia de "feirinha" ${ }^{11}$ ". Para finalizar seu comentário, a apresentadora interroga a respeito do papel exercido pela Funai Fundação Nacional do Índio, como se pode ver em SE8:

\footnotetext{
${ }^{11}$ De acordo com a fala da delegada Rosely Galego, em conversa com a agente de saúde da aldeia, liderança indígena, "feirinha" é um tipo de brincadeira em que vários homens pegam uma mulher. No caso do crime em investigação na época, o termo consistiu na prática de estupro de uma criança por um grupo de homens.
} 
SE8: e o mais revoltante, quando a justiça tenta retirar essas meninas, em situação de risco, das famílias indígenas, a Funai intervém, e atravanca o processo de transferência para uma casa-abrigo, sob a justificativa de que a cultura precisa ser preservada. Pelo amor de Deus! (DIÁRIO DIGITAL - transcrição livre).

$\mathrm{Na}$ última sequência enunciativa - a SE8 - a apresentadora qualifica como "mais revoltante" o fato de que, quando a justiça brasileira tenta tirar menores de idade, que ela rotula como crianças em "situação de risco", a Funai atua no impedimento, intervenção que, nos ditos da jornalista, acaba "atravancando" a transferência para abrigos. Ironizando a justificativa do órgão: "a cultura precisa ser preservada", o discurso midiático em funcionamento novamente promove segregação, pois "desconsidera as singularidades das crianças e adolescentes que se desenvolvam em um ambiente diferente como o indígena" (OLIVEIRA, et al., 2013, p. 305) e apaga o caráter cultural patriarcal do crime de estupro, relacionando-o estritamente a uma suposta identidade homogênea e intrínseca à natureza indígena, ligada à barbárie. Na grande maioria dos dizeres da reportagem, aliás, o crime de estupro é apagado ou, ao menos, fica em segundo plano mediante a afirmação dessa suposta identidade e a negação da diversidade cultural, como discutimos.

Finalmente, em demonstração verbal explícita de que a diversidade cultural não precisa ser preservada, a jornalista encerra sua fala com o uso da interjeição "Pelo amor de Deus". A inserção de uma formação discursiva religiosa traduziria, nesse desfecho, sua indignação com a postura assumida pela Funai, uma indignação cujos efeitos apenas mantêm a regularidade discursiva de tantos sentidos em deslizamento no enquadramento analisado.

\section{CONSIDERAÇÕES FINAIS}

Com base nas perspectivas teóricas adotadas e nos objetivos estabelecidos neste texto, vimos que a discursivização midiática do crime favoreceu a produção de um discurso preconceituoso, de disseminação de ideias discriminatórias sobre os indígenas, sobre a forma como são entendidos pela justiça e pelos órgãos de proteção a tais povos, de modo a segregar e, ao mesmo tempo, homogeneizar sua cultura e promover a manutenção dos ideais ocidentais de vida, de sociedade e, em última instância, de indianidade.

Por fim, ressaltamos que a compreensão do movimento midiático discutido aqui é um convite a um envolvimento maior com a história já escrita da cultura indígena e com os próximos episódios de um movimento de negação dos direitos humanos básicos, que vem se desenhando a cada dia com mais força na sociedade contemporânea. Na materialidade dos ditos e escritos sobre tais povos, a produção de sentidos marca a vida em sua plenitude também no jornalismo de nosso tempo: navegar por essa discursividade é, pois, mais que um gesto de análise, uma compreensão do ontem, do hoje e uma projeção do amanhã. 
ALENCAR, J. Iracema. Lenda do Ceará. São Paulo: Editora Três, 1972.

BAUMAN, Z. Modernidade Líquida. Tradução de Plínio Dentzien. Rio de Janeiro: Zahar, 2001.

BORGES, A. A. da C. O corpo indígena enredado no corpo da cidade: efeitos no/do discurso. In: INDURSKI, F.; FERREIRA, M. C. L.; MITMANN, S. (Org.). O acontecimento do discurso no Brasil/Campinas, SP: Mercado de Letras, 2013, p. 249-262.

BRASIL. Constituição da República Federativa do Brasil de 1988. Disponível em:

http://www.planalto.gov.br/ccivil_03/constituicao/ConstituicaoCompilado.htm. Acesso em: 07 set. 2015, às $13 \mathrm{~h} 25 \mathrm{~min}$.

BUTLER, J. Gender trouble, feminist theory, and psychoanalytic discourse. Feminism/postmodernism, v. 327, p. 324-340, 1990.

FOUCAULT, M. Microfísica do poder. Organização e tradução de Roberto Machado. Rio de Janeiro: Edições Graal, 1979.

FOUCAULT, M. A arqueologia do saber. Tradução de Luiz Felipe Baeta Neves. 7. ed. Rio de Janeiro: Forense Universitária, 2010a.

FOUCAUlT, M. A ordem do discurso. Tradução de Laura Fraga de Almeida Sampaio. 20. ed. São Paulo: Edições Loyola, 2010b.

FOUCAULT, M. A verdade e as formas jurídicas. Tradução de Roberto Cabral de Melo Machado e Eduardo Jardim Morais, supervisão final do texto Léa Porto de Abreu Novaes. - Rio de Janeiro: NAU Editora, 2002.

GIDDENS, A. A constituição da sociedade. Tradução Álvaro Cabral. 3. ed. São Paulo: Editora WMF Martins Fontes, 2009.

GOMES, N. L. Educação e diversidade étnico-cultural. In: MEC. Diversidade na educação: reflexões e experiências. Brasília: MEC, 2003. p. 66-76.

GREGOLIN, M. do R. Foucault: o discurso nas tramas da História. In: FERNANDES, C.; SANTOS, J. B. C. (Org.). Análise do Discurso: unidade e dispersão. Uberlândia: Entremeios, 2004, p. 19-42.

HALL, S. Who needs 'identity'? In: GAY, P. D.; EVANS, J. E. et alii (Ed.). Identity: a reader. London, Thousand Oaks, New Delhi: SAGE Publications, 2000.

HALL, S. A identidade cultural na pós-modernidade. 11. ed. Trad. Tomaz Tadeu da Silva, Guacira Lopes Louro. Rio de Janeiro: DP\&A, 2006.

INCORPORAR. Dicionário Priberam da Língua Portuguesa [em linha], 2008-2013. Disponível em: https://www.priberam.pt/DLPO/incorporar. Acesso em: 8 set. 2015.

LIMA, A. C. de. Um grande cerco da paz. Poder tutelar, indianidade e formação do Estado no Brasil. Petrópolis: Vozes, 1995.

MAHER, T. M. Ser professor sendo índio: questões de lingua(gem) e identidade. 1996. 262 f. Tese (Doutorado em Linguística) - Universidade Estadual de Campinas, Campinas-SP, 1996.

MAHER, T. Sendo índio na cidade: mobilidade, repertório linguístico e tecnologias. Revista da ANPOLL, v. 1 , n. 40 , p. 58-69, 2016 a.

MAHER, T. Do étnico ao pan-étnico: negociando e performatizando identidades indígenas. DELTA: Documentação e Estudos em Linguística Teórica e Aplicada, v. 32, n. 3, p. 719-733, 2016 b.

MIGNOLO, W. D. Histórias Locais/Projetos Globais: colonialidade, saberes subalternos e pensamento liminar. Tradução de Solange Ribeiro de Oliveira. - Belo Horizonte: Editora UFMG, 2003.

MUSSI, V. P. L. Culturas e história dos povos indígenas $-3^{\circ}$ módulo - História Indígena. Campo Grande: Ed. UFMS, 2014.

MUSSI, V. P. L.; CALDERONI, V. A. M. O. Culturas e história dos povos indígenas $-5^{\circ}$ módulo desconstruindo preconceitos sobre os povos indígenas. Campo Grande: Ed. UFMS, 2014.

OLIVEIRA, R. C. de. O processo de assimilação dos Terena. Rio de janeiro: Museu Nacional, 1960. OLIVEIRA, G. A; BERLOFFA, M. I.; SANTOS, M. A.; NERY, W. C. A diferença indígena entre memórias e silenciamentos. In: LAGAZZI, S.; ROMUALDO, E. C.; TASSO, I. (Org.). Estudos do texto e do discurso: o discurso em contraponto: Foucault, Maingueneau e Pêcheux. São Carlos: Pedro \& João Editores, 2013. p. 289-309.

SANTOS, Elaine de Moraes; BIONDO, Fabiana. Indianidade e diversidade: o discurso midiático sobre crime de estupro na aldeia Bororó. Linguagem em (Dis)curso - LemD, Tubarão, SC, v. 20, n. 2, p. 271-287, maio/ago. 2020. 
O POVO brasileiro (Matriz Tupi) 1/30. Disponível em:

https://www.youtube.com/watch?v=pwQyYRGUS4c. Acesso em: 3 jul. 2014.

ORLANDI, E. P. Interpretação; autoria, leitura e efeitos do trabalho simbólico. Petrópolis, RJ: Vozes, 1996.

OS RITUAIS dos Sonacirema - Horace Minner. Disponível em:

https://www.youtube.com/results?search_query=os+nacirema. Acesso em: 6 set. 2014.

PINTO, R. P. Classifying the brazilian population by colour: underlying problems. In: Fundação Carlos Chagas (Ed.). Brazilian issues on education gender and race. São Paulo: Fundação Carlos Chagas, 1996.

RIBEIRO, D. O povo brasileiro: A formação e o sentido de Brasil. 2. ed. São Paulo: Companhia das Letras, 1995.

SANTAELLA, L. Linguagens líquidas na era da mobilidade. São Paulo: Paulus, 2007.

SANTIAGO, S. A literatura brasileira da perspectiva pós-colonial - um depoimento. Conferência de encerramento do III COLÓQUIO NECC: ENTRELUGARES PÓS-COLONIAIS (6 de maio a 27 de junho) em 27 de junho de 2014, como parte do PROJETO DE EXTENSÃO ( ${ }^{\circ}$ do protocolo UFMS: 173883,793.1740.28032014) proposto pelo NECC: NÚCLEO DE ESTUDOS CULTURAIS COMPARADOS, sob a coordenação do prof. Edgar Cézar Nolasco.

URQUIZA, A. H. A.; PEREIRA, L. M.; PRADO, J. H. Culturas e história dos povos indígenas - $2^{\circ}$ módulo - Antropologia Indígena. Campo Grande: Ed. UFMS, 2014.

URQUIZA, A. H. A. et al., V. P. L. Antropologia indígenas - $2^{\circ}$ módulo - História Indígena. Campo Grande: Ed. UFMS, 2014.

WARREN, I. S. Educação popular e diálogo intercultural. Revista de Educação Pública, Cuiabá, v. 11, n. 19, jan-jun. 2002.

\section{DADOS DE CORPUS}

Menina de 9 anos pode ter sido estuprada por 15 homens. Vídeo disponível em: http://www.diariodigital.com.br/videos/menina-de-9-anos-pode-ter-sido-estuprada-por-15homens/7331/. Acesso em: 8 set. 2015.

Menina de 9 anos pode ter sido estuprada por 15 homens. Texto disponível em: http://www.diariodigital.com.br/politica/menina-de-9-anos-pode-ter-sido-estuprada-por-15homens/120562. Acesso em: 8 set. 2015.

Povos Indígenas: conhecer para transformar. Parte I. Museu do Índio - Botafogo (RJ). Disponível em: https://www.youtube.com/watch?v=Tf-tOJGRYOI . Acesso em: 1 set. 2014.

Povos Indígenas: conhecer para transformar. Parte II. Museu do Índio - Botafogo (RJ). Disponível em: https://www.youtube.com/watch?v=0jaRIOKOrms. Acesso em: 1 set. 2014.

Povos Indígenas: conhecer para transformar. Parte III. Museu do Índio - Botafogo (RJ). Disponível em: https://www.youtube.com/watch?v=VZmWUF3e75Ib. Acesso em: 1 set. 2014.

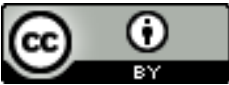

Este texto está licenciado com uma Licença Creative Commons Atribuição 4.0 Internacional. 